\title{
ESTUDO E DESENVOLVIMENTO DO CONTROLE DO AVANÇO DE IGNIÇÃO EM UM MOTOR FLEX
}

\author{
Paulo Alexandre Pizará Hayashida ${ }^{1}$, Lucas Motta de Novaes ${ }^{1}$, João Francisco Justo ${ }^{1}$, \\ Armando Antonio Maria Lagana ${ }^{1}$, Kleber Nogueira Hodel $^{1}$ e Marco Isola Naufal ${ }^{2}$. \\ ${ }^{1}$ Escola Politécnica da Universidade de São Paulo \\ ${ }^{2}$ Instituto de Pesquisas Tecnológicas

\begin{abstract}
E-mails: paulo.hayashida@usp.br,lnovaes.motta@usp.br, jiusto@lme.usp.br, lagana@1si.usp.br, a.hodel@yahoo.com.br, mnaufal@ipt.br
\end{abstract}

\section{RESUMO}

O presente trabalho propõe o estudo e desenvolvimento de um algoritmo para controle do avanço de ignição em malha fechada para um motor Flex de 1.61 utilizando uma unidade de desenvolvimento modelo Flex-ECU através do software ASCET. A relação entre o torque produzido pelo motor em função de parâmetros como: avanço de ignição, rotação do motor, carga (pressão do ar admitido), fator ar/combustível da mistura e da composição do combustível é estudada, a fim de se obter o mapa base de avanço que produza o maior torque possível para cada condição sem a ocorrência de detonação no motor. A partir dos dados coletados e análises complementares em relação à pressão de combustão do cilindro, temperatura do gás de escape e indicador sonoro da detonação, o comportamento da detonação para o presente motor é estudado para o desenvolvimento do controle do avanço em malha fechada, permitindo o gerenciamento obter o maior torque de saída o possível independentemente da composição do combustível utilizado e de perturbações no sistema.

\section{INTRODUÇÃO}

A preocupação com a emissão de poluentes, produzidos por veículos automotores que utilizam gasolina e óleo diesel, e seu impacto ao meio ambiente, tem fomentado intensivas pesquisas por fontes alternativas de combustíveis ou por desenvolvimento de motores a combustão interna mais eficientes. Na área de fontes alternativas, diversas opções vêm sendo consideradas, por exemplo, os biocombustíveis, como biodiesel e etanol como alternativas para o óleo diesel e gasolina, respectivamente [1] [2].

Atualmente, o etanol é utilizado como misturado ou substituto da gasolina, principalmente no Brasil, ou como aditivo em países como EUA, Canadá e Índia [2] [3] [1]. No Brasil dois tipos de etanol são produzidos, o etanol anidro, que é misturado à gasolina (Tipo A) para produção da gasolina E27 (Tipo C) e o etanol hidratado. Segundo [4] as vendas de gasolina E27 no Brasil pelas distribuidoras foram de 43 milhões de $\mathrm{m}^{3}$, sendo está composta de 31,4 milhões de $\mathrm{m}^{3}$ de gasolina (Tipo A) e 11,6 milhões de $\mathrm{m}^{3}$ de etanol anidro, enquanto o etanol hidratado foi de 14,6 milhões de $\mathrm{m}^{3}$.

Esses álcoois apresentam características interessantes, como alta octanagem e alto calor de vaporização, o que aumenta a resistência do combustível à detonação, possibilitando que o motor trabalhe com taxas de compressão maiores do que quando se utiliza gasolina, e diminuindo o pico de temperatura na câmara de combustão, levando a maior resistência 
contra detonação, redução da emissão de óxidos de nitrogênio (NOx), acréscimo da potência de saída do motor, menor intervalo entre a ignição e o início da combustão e maior velocidade de propagação da chama [2] [3] [5].

A adição de etanol à gasolina propicia uma melhoria nas características do combustível, como: torque de saída, consumo e redução da emissão de monóxido de carbono (CO) e hidrocarbonetos (HC) entre $10-90 \%$ e $20-80 \%$, respectivamente, dependendo da condição de funcionamento do motor [6]. A adição de etanol à gasolina altera a relação estequiométrica do combustível com o ar, uma vez que o etanol possui oxigênio em sua estrutura molecular, reduzindo o número de moléculas necessárias para a combustão ideal do combustível, sendo a relação estequiométrica do álcool de 8.98:1 e da gasolina 14.58:1 [7] [2]. Sendo assim, as diferentes características do etanol, gasolina e de suas misturas requerem que o gerenciamento de parâmetros do motor, como o tempo de injeção de combustível e o avanço do ponto de ignição, sejam realizados em função da composição do combustível utilizado, de modo a se maximizar o torque de saída do motor, reduzir a emissão de poluentes e evitar a ocorrência de detonação.

A detonação é um fenômeno decorrente da autoignição espontânea da mistura de ar e combustível dentro do cilindro. A detonação provoca uma súbita elevação da pressão dentro do cilindro que reduz a eficiência do motor, produz ruídos e pode quando não suprimido causar danos a motor [8]. Segundo esses autores, devido à aleatoriedade das causas do fenômeno como variação da massa residual da combustão e pontos quentes, a predição do fenômeno é praticamente impossível para sistemas em tempo real. A prevenção da detonação é, então, realizada pelo gerenciamento do motor através da alteração do ponto de avanço de ignição, que altera a eficiência do ciclo e as chances de ocorrer detonação [8].

\section{ETANOL NO BRASIL}

O etanol tem grande importância no mercado nacional de combustíveis atualmente, pois o etanol anidro corresponde a $27 \%$ do volume da gasolina comercializada ao consumido e o etanol hidratado corresponde a $25 \%$ do combustível liquido para veículos comerciais distribuído no ano de 2016 [4]. Entretanto, a história do etanol no mercado nacional tem seus primeiros registros no ano de 1925 , em que o decreto $n^{\circ} 19.717$ de 20 de fevereiro de 1931 instituiu que a partir do dia $1^{\circ}$ de julho daquele mesmo ano seria obrigatório a adição de $5 \%$ de etanol na gasolina de origem importada [9] [10].

Em 1933, foi fundado Instituto do Açúcar e do Álcool (IAA) durante o governo de Getúlio Vargas pelo decreto $\mathrm{n}^{\circ} 22.789$, que permitia o Estado intervir no mercado por meio de fixação dos preços, monopolização das compras, regulando o transporte, manuseio e armazenamento do açúcar e do álcool [11] [12]. E através da Lei $n^{\circ} 737$, a imposição de 5\% de etanol na gasolina foi ampliada para a gasolina produzida no Brasil [13]. Essas ações do governo tinham como objetivo criar um mercado alternativo para o açúcar, no qual se acreditava que o açúcar produzido excedia as necessidades do mercado e reduzir a dependência do petróleo estrangeiro [11] [14] [15].

O Programa Nacional do Álcool (PROÁLCOOL) é criado em 1975 através do decreto ${ }^{\circ}$ 76.593, com o intuito de incentivar o mercado nacional do álcool em resposta à crise do petróleo de 1973 [11] [16]. O programa pode ser caracterizado em quatro fases segundo [11], a primeira fase (1975-1979) havia incentivos para a indústria a fim de se aumentar da produção de etanol anidro que era misturado na gasolina; a segunda fase (1980-1985) incentivava a produção do etanol hidratado que tinha como objetivo a utilização em motores 
desenvolvidos especialmente para este fim; a terceira fase (1988-2002) é conhecida como o período de crise, onde devido a altos custos de produção em relação a gasolina, falta de subsídios para produção e redirecionamento das usinas para produção de açúcar levaram ao desabastecimento e descrença do etanol. Durante este período, o PROÁCOOL foi interrompido como programa governamental. E em 1993 através da lei no 8.723/1993 é estabelecida a obrigatoriedade da adição de 20 a $25 \%$ de etanol anidro à gasolina [11] [17].

A última fase (2002-) corresponde a uma nova ascensão do etanol no mercado, impulsionado pela crescente preocupação em relação a emissão de poluentes e a chegado dos motores flexfuel ao mercado, que podem operar com gasolina, etanol anidro ou qualquer mistura entre eles [11].

\section{FENÔMENO DA DETONAÇÃO}

Durante a fase de compressão, a combustão da mistura ar combustível pode ocorrer de maneira normal ou anormal, sendo que a última se caracteriza pelo fenômeno da detonação. Esse fenômeno, segundo [18], pode ocorrer devido à autoignição da mistura que ainda não foi queimada. Esta fração da mistura é comprimida e aquecida pela frente de chama do processo de combustão, levando essa parte da mistura a entrar em autoignição, originando uma segunda frente de chama. Quando a frente de chama iniciada pela centelha da vela de ignição se choca com a frente de chama da autoignição, aparecem picos na pressão que excitam reverberações acústicas [19].

\subsection{Controle do avanço de ignição}

O método do controle do avanço de ignição funciona da seguinte maneira: a unidade de controle do motor possui um mapa base do ângulo de ignição e, a partir disso, o parâmetro de controle do ângulo de ignição $\alpha \mathrm{k}(\mathrm{n})$ é calculado e somado ao mapa base do ângulo de ignição. Este parâmetro é, então, calculado para cada ciclo de combustão n pela equação (1) [19].

$$
\alpha_{\mathrm{k}}(\mathrm{n})=\mathrm{a}_{\mathrm{k}}(\mathrm{n}-1)+\Delta \mathrm{a}_{\mathrm{k}}-\left(\beta \times \Delta \mathrm{E}_{\mathrm{y}}(\mathrm{n})\right)
$$

onde $\Delta \alpha \mathrm{k}$ é um avanço de ignição permanente e o termo $\beta \times \Delta \mathrm{E}_{\mathrm{y}}(\mathrm{n})$ é o atraso de ignição quando ocorre a detonação. Por segurança, o valor de $\alpha \mathrm{k}(\mathrm{n})$ deve ser sempre menor ou igual a 0 [19].

Segundo [19], este controle é útil para se compensar variações de parâmetros relativas à: temperatura ambiente, pressão ambiente, octanagem do combustível, tolerância no processo de fabricação do motor e envelhecimento do motor.

\section{METODOLOGIA}


A investigação é executada no veículo Volkswagen Gol 1.6 modelo. Este motor possui uma taxa de compressão de 12:1, sendo assim, um motor que utiliza uma taxa de compressão intermediária em relação a motores a gasolina e motores e etanol. Este motor possui sistema de alimentação de combustível indireta múlti ponto, e sistemas de ignição e válvula borboleta eletrônica, permitindo o controle desses componentes.

A plataforma que será utilizada para o gerenciamento eletrônico do motor e implementação dos controladores é a FlexECU. O software de aplicação utilizado é o Otto-3, desenvolvido por [25] usando o software ASCET, e seus parâmetros são ajustados através do software INCA.

A detecção da ocorrência de detonação é realizada através do indicador de detonação. Este sistema lê o sinal do sensor acelerômetro instalado no corpo do motor através da FlexECU, então o sinal e filtrado, amplificado e integrado digitalmente, o resultado da integração se correlaciona com a ocorrência de detonação. Como método secundário o sinal do sensor acelerômetro é submetido a um alto-falante a fim de se detectar a ocorrência de detonação através de seu ruído característico.

O sistema desenvolvido e descrito na seção (4) é validado e os resultados são discutidos na seção (5). A validação do sistema consiste em comparar o torque de saída do motor com o sistema de controle ativo e desativado para as seguintes condições: carga máxima $(90 \mathrm{kPa}$ de pressão de admissão), fator lambda de referência da mistura igual a 1, rotações de 2000, 3000 e 4000 RPM e composição de gasolina com 35\% de etanol (E35) e etanol hidratado (E95).

\section{PROJETO}

O projeto consiste no desenvolvimento de uma função para detecção da ocorrência de detonação e controle do avanço de ignição em função da mesma.

\subsection{Controle do avanço em malha fechada}

O controle do avanço de ignição é realizado em malha fechada através da informação relativa à integral do sinal proveniente de um acelerômetro, onde o processamento digital do sinal é realizado pelo LLSW. Para isso, é necessário informar os seguintes parâmetros: o filtro que será utilizado, o valor do amplificador digital, a posição de início da janela de integração e a largura da janela de integração. Como resposta, o LLWS irá retornar o valor da integração, qual cilindro estava em processo de combustão durante a integração e se houve algum erro durante a leitura. A figura (1) ilustra a programação desenvolvida no ambiente ASCET para configuração dos parâmetros utilizados para leitura da detonação. 
Figura 1 - Configuração do LLSW para leitura dos parâmetros relativos a detonação.

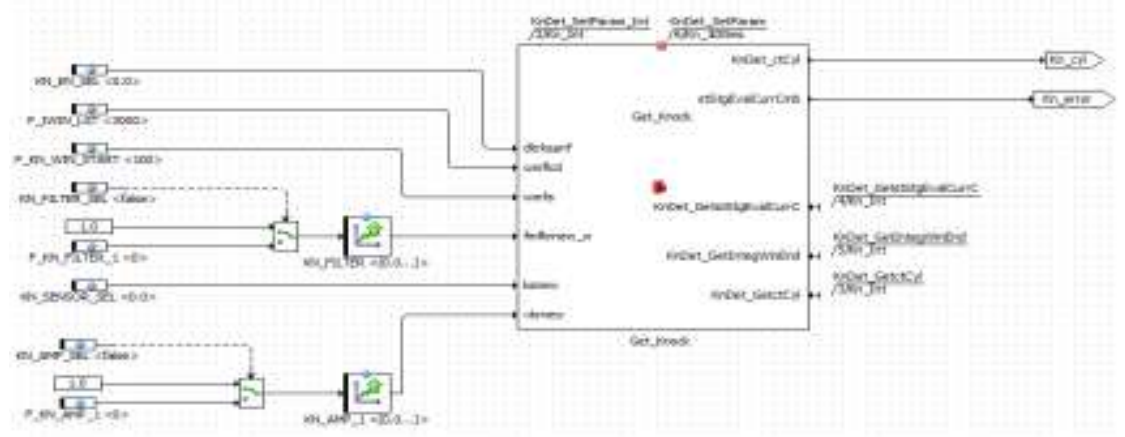

Fonte: Autor

A partir do resultado da integração foi desenvolvido um sistema para constatação de detonação. A leitura da integral é realizada a cada ciclo de combustão do motor. Se esta o valor da integral for menor do que o valor calibrado pela variável KN_TRIG_FIRST, é então adicionado um offset de $1,5^{\circ}$ ao avanço de ignição base. Se a leitura seguinte for menor novamente, o offset será adicionado novamente, repetindo-se o ciclo com um limite definido pela variável KN_MAX_DELTA, sendo que este valor pode ser calibrado, mas é utilizado o valor de $8^{-}$como valor padrão.

Caso o valor da integral seja maior do que KN_TRIG_FIRST, serão retirados $0,75^{\circ}$ do offset que foi adicionado ao avanço, com o objetivo de se suprimir a ocorrência de detonação, porém caso o valor ultrapasse KN_TRIG_SECN o offset será zerado. Tal sistema é ilustrado através da figura (2).

Figura 2 - Módulo de controle do avanço em função da detonação.

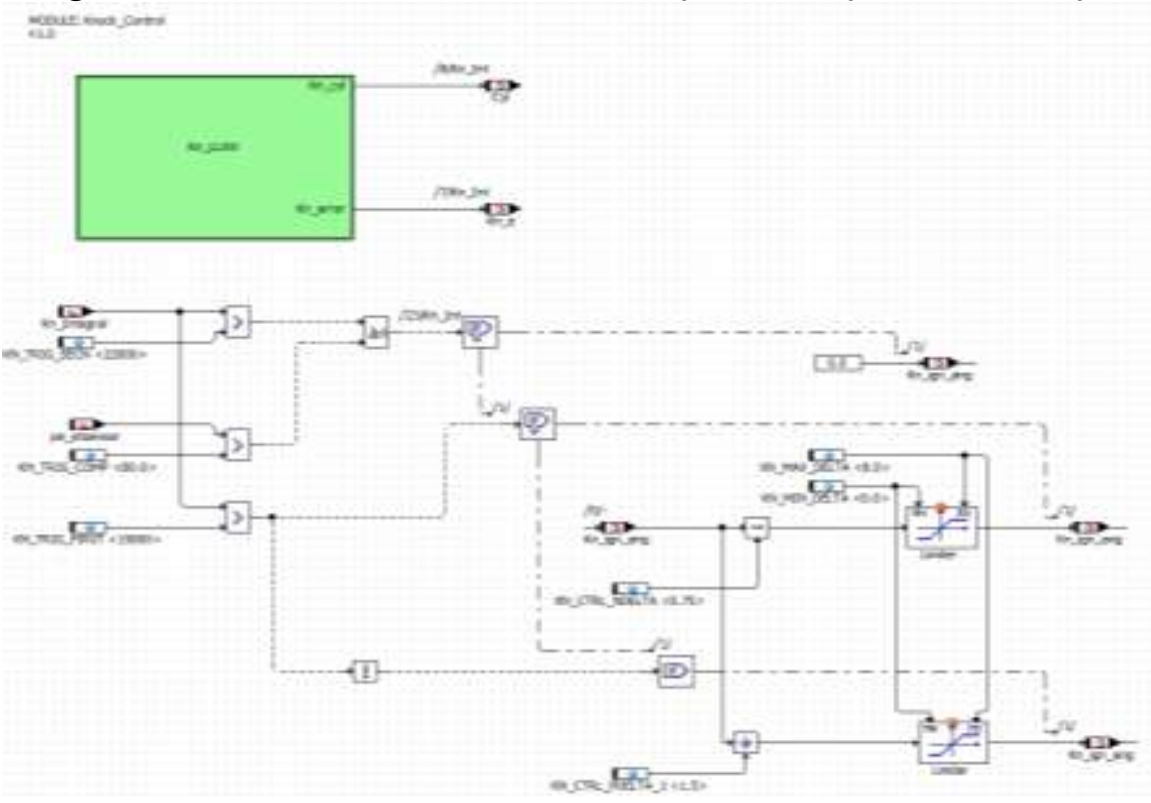

Fonte: Autor.

\section{RESULTADOS}


Esta seção apresenta o resultado da validação do controle em malha fechada do avanço de ignição em função da detonação. Os testes são realizados com os seguintes parâmetros: composição de combustível de 35 e $91 \%$ de etanol, carga máxima do motor ( $90 \mathrm{kPa}$ ), rotações de 2000, 3000 e 4000 RPM, com o controle ativo ou desativado, a fim de comparar os valores de torque de saída do motor, valor do indicador de detonação, média do indicador de detonação e o avanço que é aplicado.

\subsection{Testes com composição de $35 \%$ de etanol}

Este teste foi realizado com as seguintes configurações: duração de 60 segundos, composição de $35 \%$ de etanol, motor com carga total e com as seguintes rotações 2000,3000 e 4000 . O teste com composição de 35\% foi realizado principalmente com a intenção de se analisar e comparar o torque de saída, o torque médio, o valor do indicador de detonação e a média do indicador de detonação com o controle ativo e desativado.

\subsubsection{Validação a 2000 RPM com composição de 35\% de etanol}

A figura (3) ilustra o resultado do teste com o controle desabilitado e a figura (4) com o controle ativo para o teste a 2000 RPM.

Figura 3 - Curvas de Indicador de detonação (a), Avanço final de ignição (b) e torque de saída do motor (c), para o teste de 2000 RPM com controle desabilitado e composição de $35 \%$ de

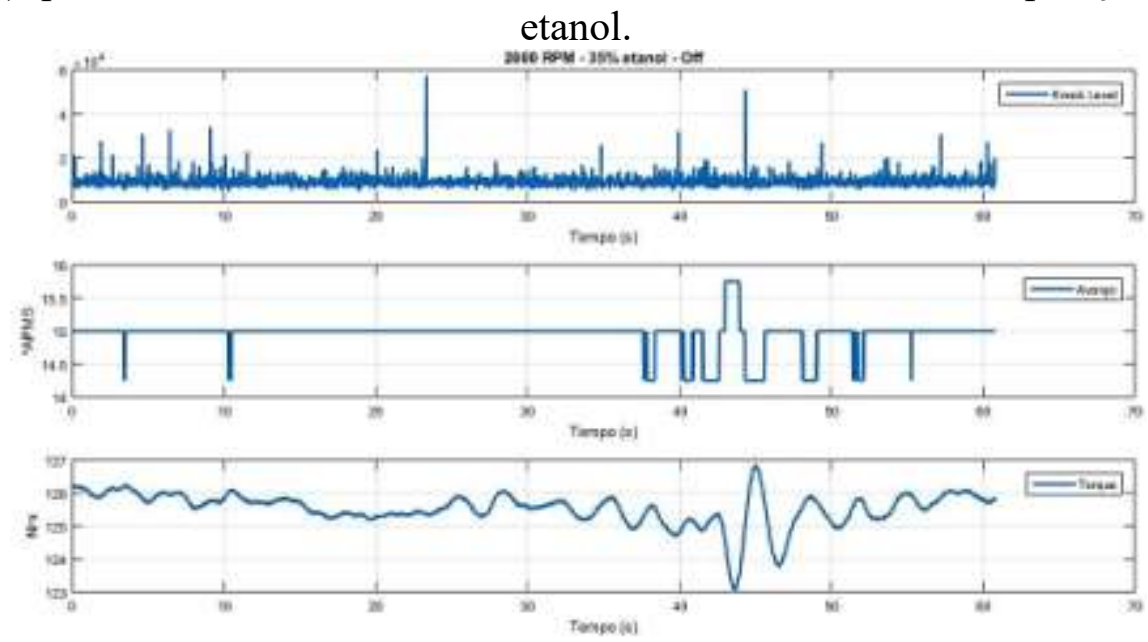

Fonte: Autor. 
Figura 4 - Curvas de Indicador de detonação (a), Avanço final de ignição (b) e torque de saída do motor (c), para o teste de 2000 RPM com controle ativo e composição de 35\% de etanol.
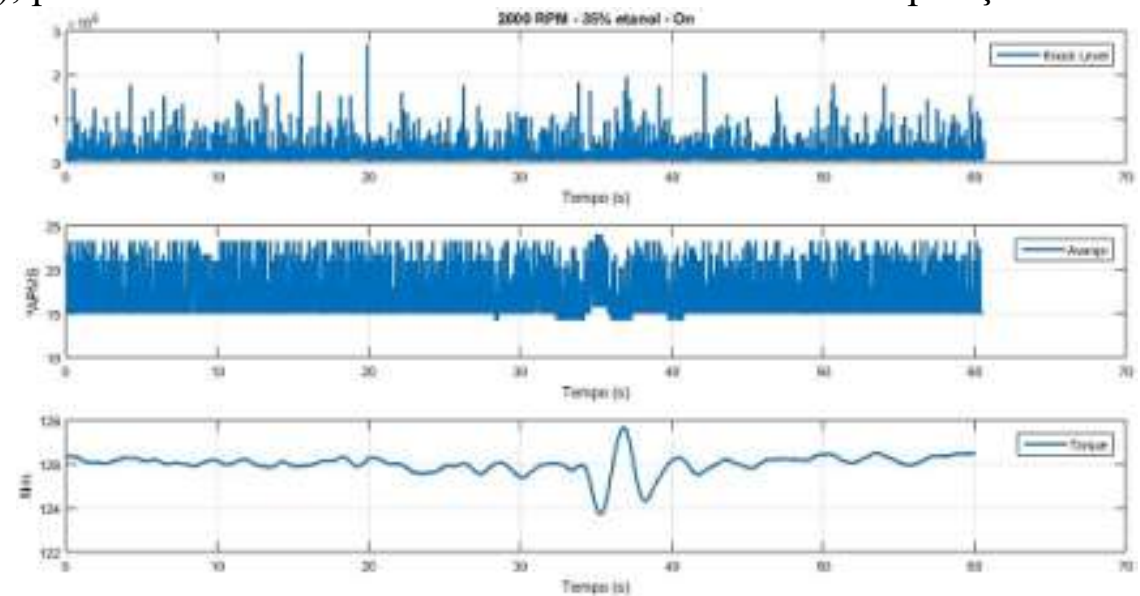

Fonte: Autor.

Analisando os resultados, inicialmente pode-se notar que o torque de saída do motor permanece mais estável quando o controle está habilitado. Adicionalmente, em ambos os testes há uma perturbação não medida no avanço de ignição. Esta perturbação, que afeta o torque de saída em aproximadamente 45 segundos do primeiro teste e em 35 segundos do segundo teste, é causada pelo avanço em função da temperatura do motor, que para o presente teste não foi medida. O valor médio do torque em ambos os testes foi de $126 \mathrm{Nm}$, mostrando que o controle não apresenta ganho relativo nesta condição de funcionamento do motor.

Em relação ao indicador de detonação, o teste com controle ativo apresentou mais picos e com maiores valores, o que era esperado, uma vez que o controle tenta fazer o motor operar na liminar de detonação.

A média do indicador com o controle desabilitado foi de 9195 e o valor com controle ativo foi de 18429, um aumento relativo entre os dois resultados, porém o valor médio com controle ativo é menor do que o liminar para redução do avanço de 22000. A partir destes resultados, observa-se que o controle não traz ganho relativo nesta condição de operação do motor, sendo melhor alterar a programação do controle para ele não atuar nesta faixa de operação.

\subsubsection{Validação a 3000 RPM com composição de 35\% de etanol}

A figura (5) ilustra o resultado do teste com o controle desabilitado e a figura (6) com o controle ativo para o teste a 3000 RPM. 
Figura 5 - Curvas de Indicador de detonação (a), Avanço final de ignição (b) e torque de saída do motor (c), para o teste de 3000 RPM com controle desabilitado e composição de $35 \%$ de etanol.
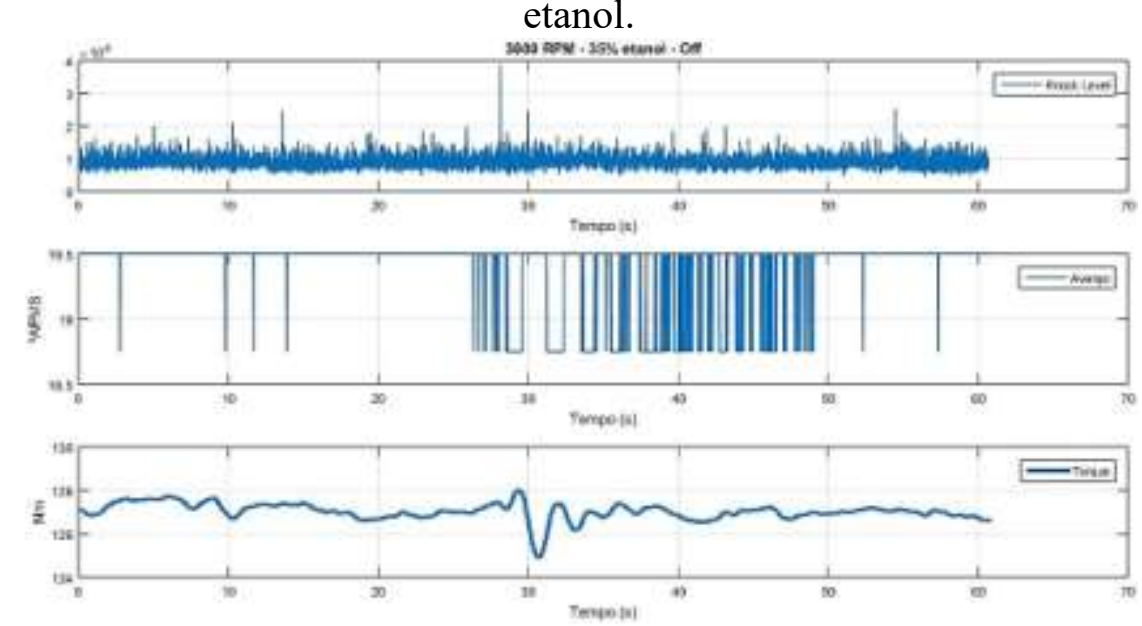

Fonte: Autor.

Figura 6 Curvas de Indicador de detonação (a), Avanço final de ignição (b) e torque de saída do motor (c), para o teste de 3000 RPM com controle ativo e composição de $35 \%$ de etanol.
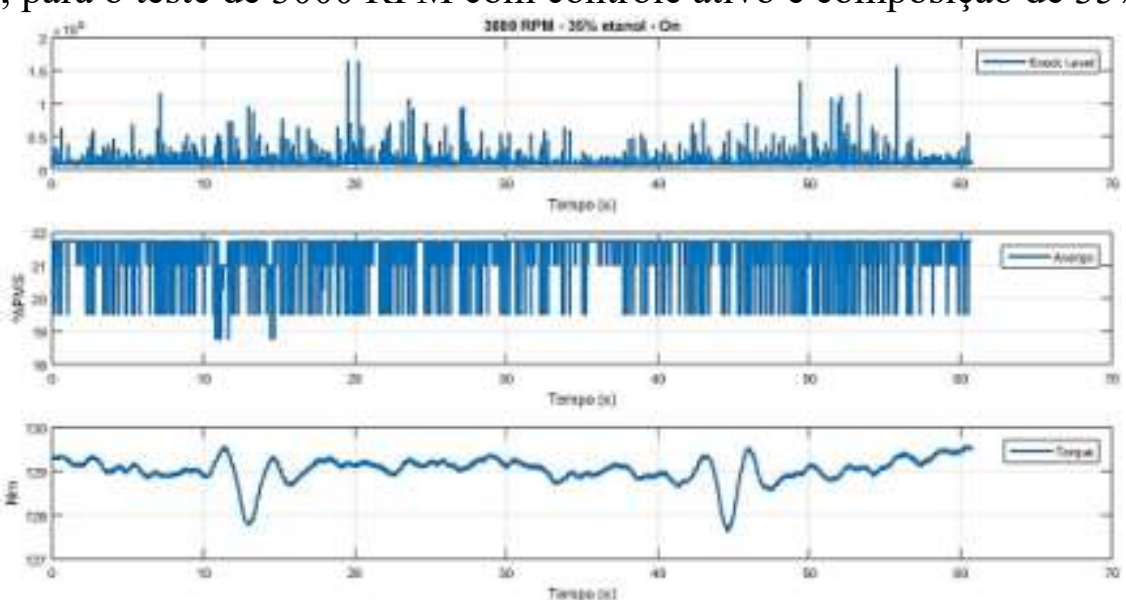

Fonte: Autor.

Primeiramente o principal resultado é que diferentemente do teste realizado a 2000 RPM, o teste a 3000 RPM com controle ativo apresenta ganho de torque em relação ao teste a 3000 RPM com controle desabilitado, sendo que o valor médio com controle ativo é de $129 \mathrm{Nm}$, enquanto com controle desabilitado o valor é de $127 \mathrm{Nm}$. Novamente em ambos os testes são observadas perturbações no sinal de saída de origem não medidas duas vezes, com o controle ativo a aproximadamente 12 e 45 segundos.

Com o controle desabilitado, a perturbação tem início há aproximadamente 30 segundos, e continua durante 20 segundos. Porém o torque só é afetado no início da perturbação, se estabilizado após a oscilação inicial.

Em relação ao valor do indicador de detonação, os resultados apresentados a 3000 RPM são muito melhores do que os a 2000 RPM, sendo o valor médio com controle ativo a 3000 RPM de 10926. Com o controle desabilitado, o valor médio é de 9145. Este resultado demonstra que o controle traz 
benefícios ao torque de saída sem comprometer a ocorrência de detonação para esta condição de operação do motor.

\subsubsection{Validação a 4000 RPM com composição de 35\% de etanol}

A figura (7) ilustra o resultado do teste com o controle desabilitado e a figura (8) com o controle ativo para o teste a 4000 RPM.

Figura 7 - Curvas de Indicador de detonação (a), Avanço final de ignição (b) e torque de saída do motor (c), para o teste de 4000 RPM com controle desabilitado e composição de $35 \%$ de
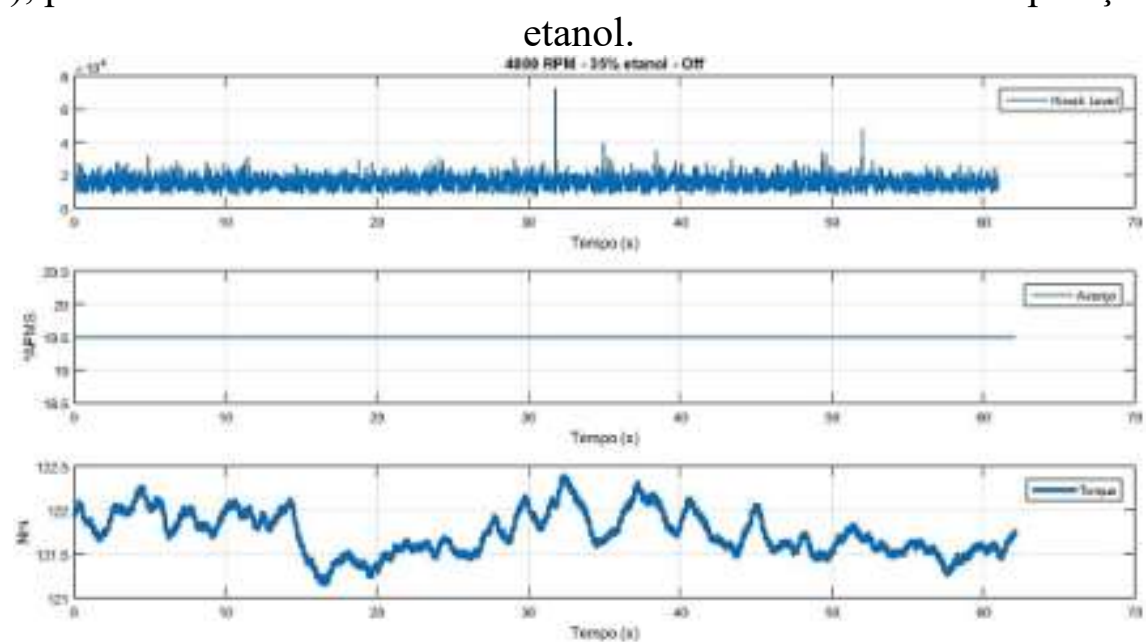

Fonte: Autor.

Figura 8 - Curvas de Indicador de detonação (a), Avanço final de ignição (b) e torque de saída do motor (c), para o teste de 4000 RPM com controle ativo e composição de $35 \%$ de etanol.
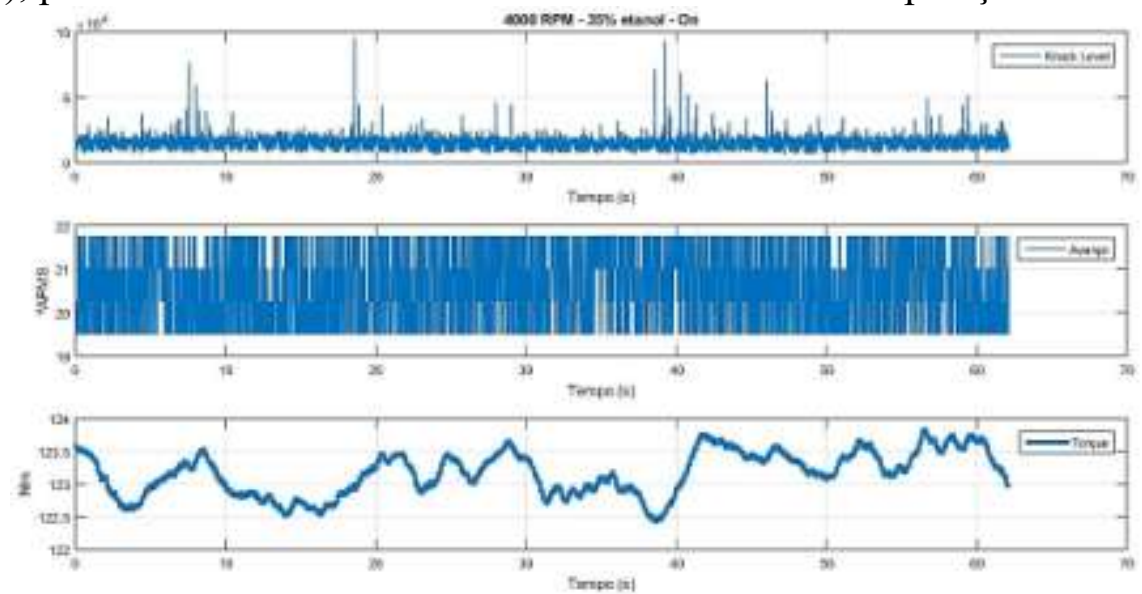

Fonte: Autor.

Finalizando os testes com composição de $35 \%$ de etanol, o teste a 4000 RPM, assim o como o teste a 3000 RPM, apresenta melhora no torque de saída do motor quando o controle está ativo em relação a torque de saída quando o mesmo está desabilitado, sendo que o valor médio com controle ativo é de $123,1 \mathrm{Nm}$ e com controle desabilitado é de 121,7 Nm. Uma particularidade deste teste é que o torque de saída não foi afetado pela perturbação não medida como nos testes anteriores, conforme mostrado no gráfico de avanço na figura 39 (b). 
Em relação ao indicador de detonação, o teste apresentou um resultado divergente aos testes anteriores, o indicador de detonação apresentou média menor com o controle ativo em relação à média com controle desabilitado, sendo de 15233 para o primeiro e de 15558 para o segundo.

Estes resultados reforça a conclusão obtida com o teste a 3000 RPM de que o controle otimiza o torque de saída sem comprometer a ocorrência de detonação.

5.2 Validação com composição de $91 \%$ de etanol

Este teste foi realizado com as seguintes configurações: duração de 60 segundos, composição de $91 \%$ de etanol, motor com carga total e com rotações de 2000, 3000 e 4000 RPM. O teste com composição de $91 \%$ foi realizado para estudar o comportamento do motor em relação à ocorrência de detonação e torque do motor e se existe algum ganho de torque em se trabalhar com o avanço de ignição na liminar de detonação. Para isso, o teste é realizado com o controle ativo e desabilitado, a fim de se comparar o torque de saída do motor com um ângulo de ignição próximo da liminar e um ângulo mais atrasado.

\subsubsection{Validação com 2000 RPM com composição de 91\% de etanol}

A figura (9) ilustra o resultado do teste com o controle desabilitado e a figura (10) com o controle ativo para o teste a 2000 RPM e composição do combustível de $91 \%$ de etanol.

Figura 9 - Curvas de Indicador de detonação (a), Avanço final de ignição (b) e torque de saída do motor (c), para o teste de 2000 rpm com controle desabilitado e composição de $91 \%$ de etanol.
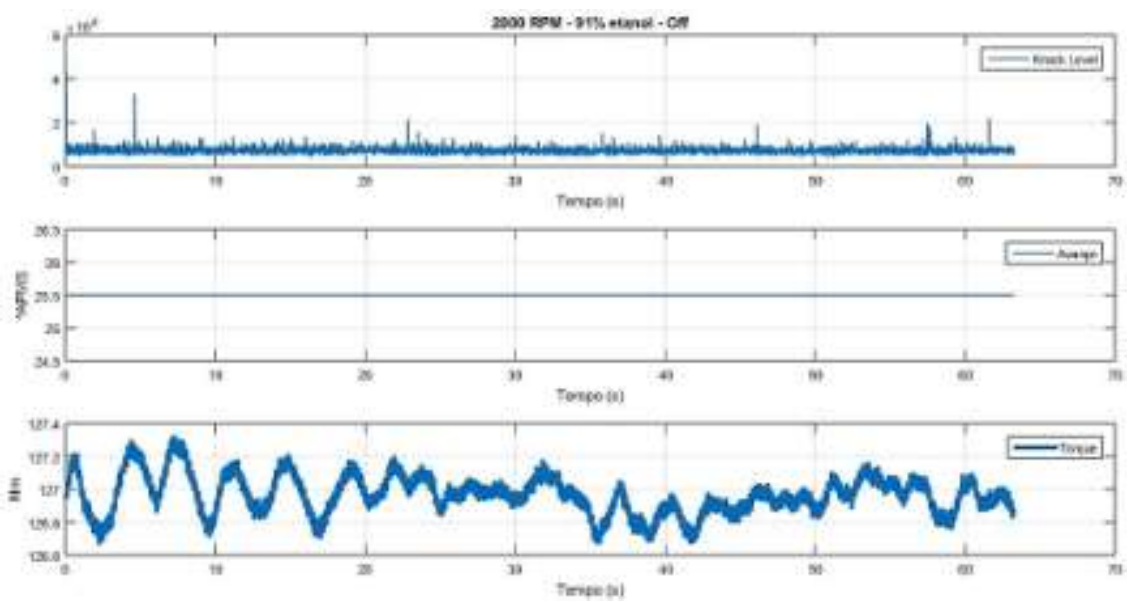

Fonte: Autor.

Figura 10 - Curvas de Indicador de detonação (a), Avanço final de ignição (b) e torque de saída do motor (c), para o teste de 2000 RPM com controle ativo e composição de $91 \%$ de etanol. 

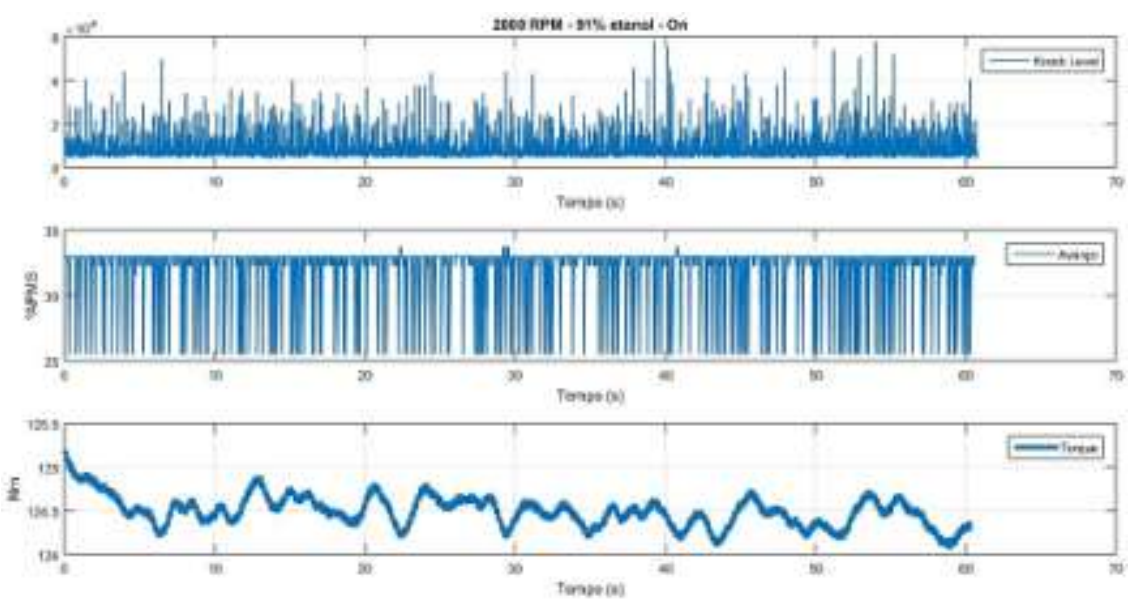

Fonte: Autor.

Analisando os resultados, é evidente que não houve ganho de torque através do controle em malha fechada, ao invés disso houve um menor torque de saída produzido em relação ao teste com controle desabilitado. Tal resultado fica evidente através da média de torque dos dois ensaios, para o controle ativado a média é $124,5 \mathrm{Nm}$ enquanto que com o controle desabilitado a média de torque é $127 \mathrm{Nm}$.

A média do indicador de detonação para o teste com controle ativo foi de 8885 , enquanto que para o teste com controle desabilitado a média foi de 7254 , assim a função executa seu objetivo de aproximar o avanço de ignição para liminar de detonação sem que ocorram detonações subsequentes.

$\mathrm{O}$ resultado indica que o controle não traz benefícios para o torque de saída, porém os testes subsequentes com 3000 e 4000 RPM irão indicar se este comportamento é devido à faixa de rotação, como observado com a composição de $35 \%$ de etanol ou se é devido a composição do combustível utilizado.

\subsubsection{Validação com 3000 RPM com composição de 91\% de etanol}

A figura (11) ilustra o resultado do teste com o controle desabilitado e a figura (12) com o controle ativo para o teste a 3000 RPM e composição do combustível de $91 \%$ de etanol. 
Figura 11 - Curvas de Indicador de detonação (a), Avanço final de ignição (b) e torque de saída do motor (c), para o teste de 3000 RPM com controle desabilitado e composição de 91\% de etanol.
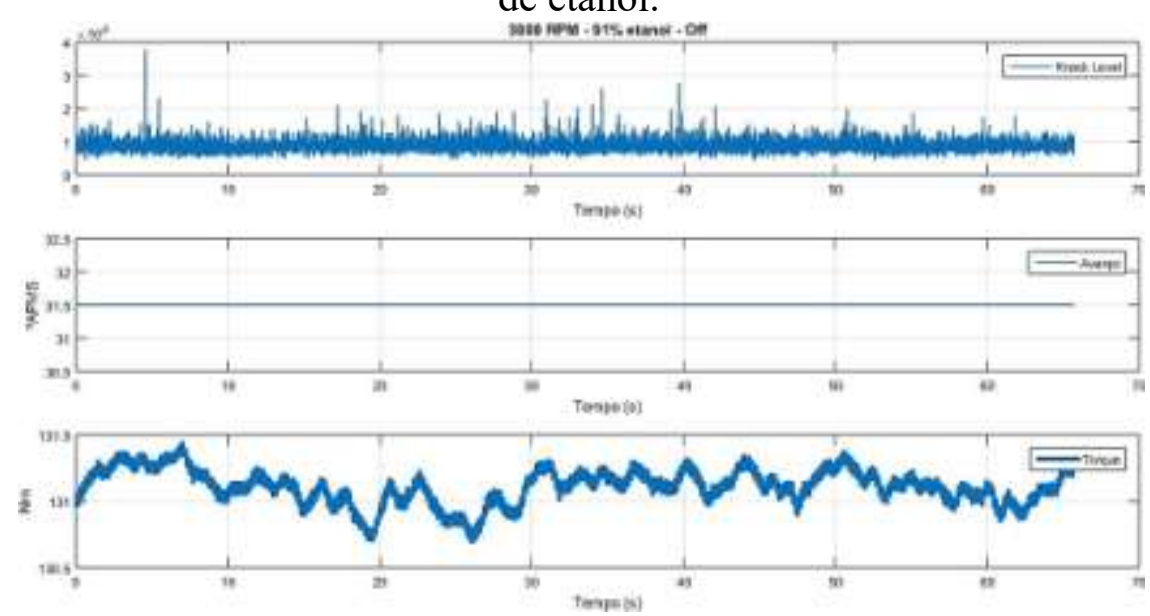

Fonte: Autor.

Figura 12 - Curvas de Indicador de detonação (a), Avanço final de ignição (b) e torque de saída do motor (c), para o teste de 3000 RPM com controle ativo e composição de $91 \%$ de etanol.
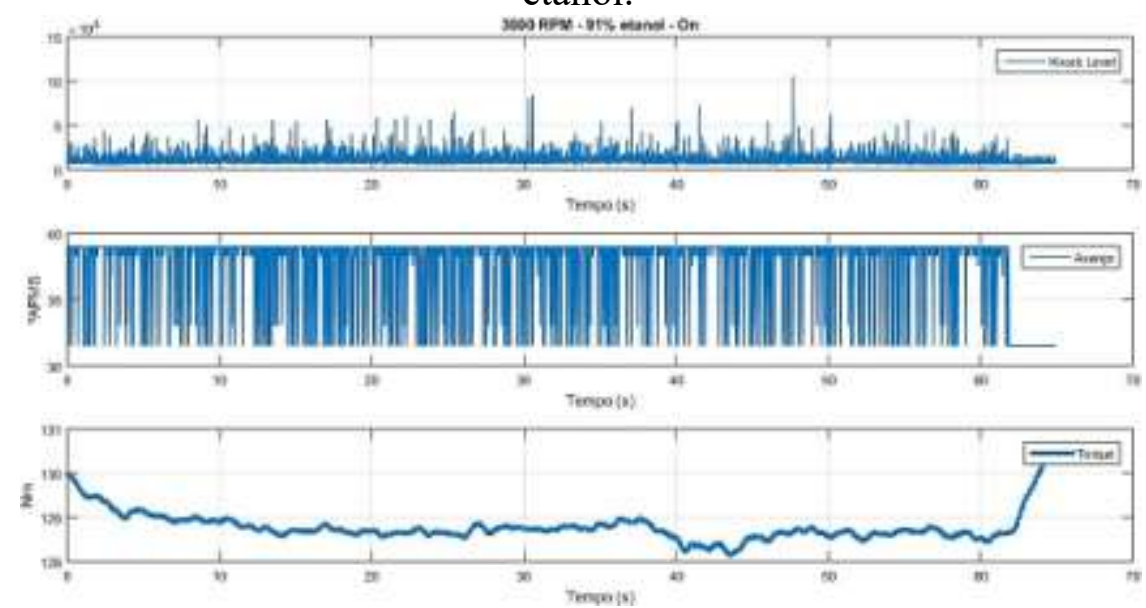

Fonte: Autor.

A análise dos resultados reforça as conclusões obtidas com o teste a 2000 RPM, novamente o torque de saída do motor foi menor quando o controle do avanço estava ativo do que quando o controle estava desabilitado. Sendo o torque médio para quando o controle está desabilitado de $131,1 \mathrm{Nm}$, enquanto com o controle ativo o torque médio é $128,8 \mathrm{Nm}$.

Em relação à média do indicador de detonação, para o teste com controle desabilitado, a média é 8903 e para o teste com controle ativado a média é 11404. Apesar da média com controle ativado ser maior do que com controle desabilitado, o controle consegue manter a média abaixo de 15000 que é o liminar para recuo do avanço.

Novamente os resultados indicam que não há ganho com o controle em malha fechada, indicando que este comportamento é devido à composição do combustível e não à faixa de operação do motor. 


\subsubsection{Validação com 4000 RPM com composição de 91\% de etanol}

As figuras (13) e (14) ilustram os resultados dos testes respectivamente com o controle desabilitado e ativo a 3000 RPM e composição do combustível de $91 \%$ de etanol.

Figura 13 - Curvas de Indicador de detonação (a), Avanço final de ignição (b) e torque de saída do motor (c), para o teste de 4000 RPM com controle desabilitado e composição de $91 \%$ de etanol.
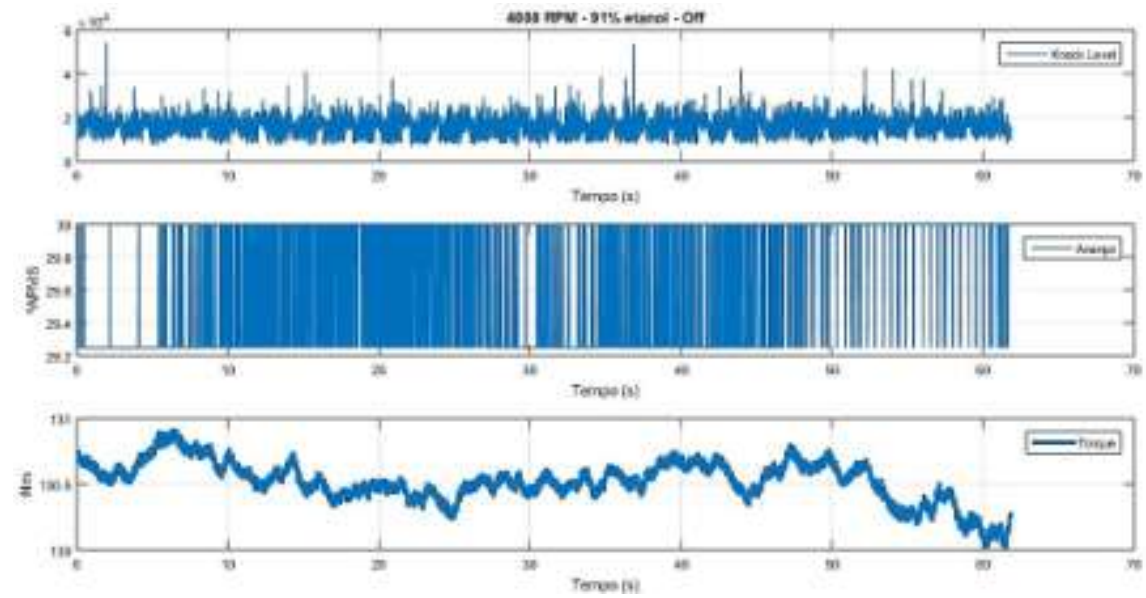

Fonte: Autor.

Figura 14 - Curvas de Indicador de detonação (a), Avanço final de ignição (b) e torque de saída do motor (c), para o teste de 4000 RPM com controle ativo e composição de $91 \%$ de etanol.
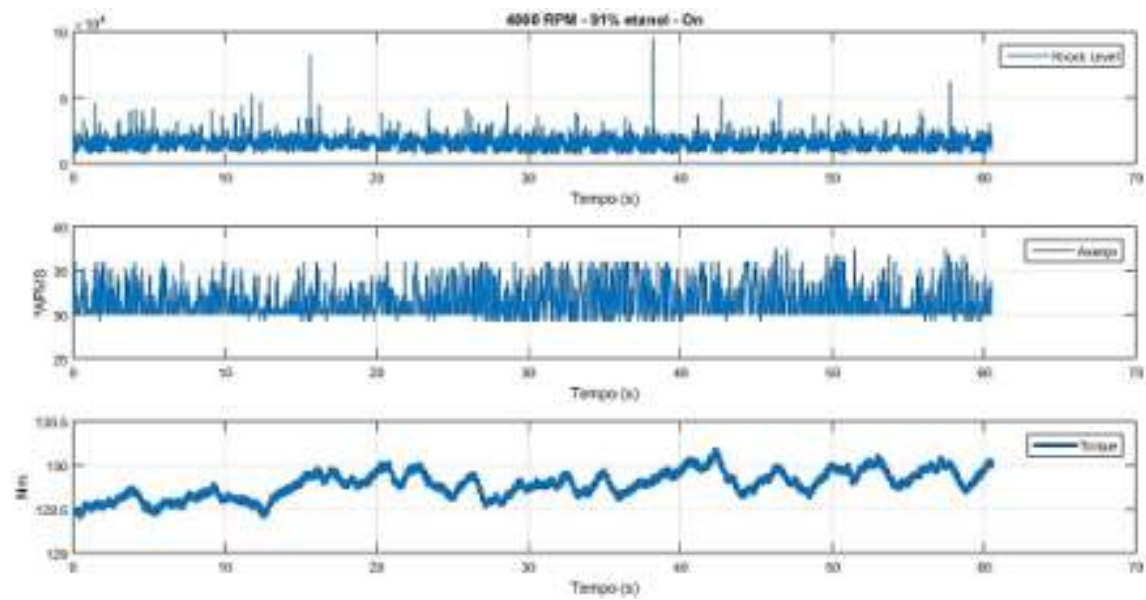

Fonte: Autor.

Finalmente, o teste com 4000 RPM reforça os resultados anteriores, apesar de a diferença entre o torque com controle ativo e desabilitado ser a menor dos três ensaios tal diferença indica novamente que trabalhar com o avanço de ignição próximo ao liminar de detonação não traz benefícios em relação ao torque de saída com composição de combustível de $91 \%$ de etanol. O torque médio do ensaio foi de $129,78 \mathrm{Nm}$ para o controle ativado e de $130,5 \mathrm{Nm}$ com o mesmo desativado. 
Em relação ao indicador de detonação ambos os resultados apresentaram média acima do valor do primeiro liminar, sendo 15957 com controle ativo e de 16572 com controle desabilitado, resultados divergentes de todos os outros testes por apresentar valor maior quando o controle estava desabilitado.

\section{CONCLUSÃO}

O sistema de controle de avanço de ignição apresenta ganho no torque de saída do motor em relação ao sistema em malha aberta para rotações acima de 2000 RPM e composições inferiores a $80 \%$ de etanol.

Os resultados obtidos com o estudo do torque de saída do motor em função da composição do combustível demonstraram que para misturas com maiores concentrações de etanol, o torque do motor decresce antes da ocorrência da detonação. Este comportamento ocorre, pois a taxa de compressão do motor estudado é menor do que a taxa ideal para etanol, assim antes da ocorrência de detonação ocorre o retardo do processo de combustão que resulta em uma maior perda térmica no processo.

A partir destes resultados o controle do avanço em função da detonação é limitado a fim de somente entrar em malha fechada quando a composição do combustível for inferior a $80 \%$ de etanol.

Os resultados obtidos podem ser utilizados como base para o desenvolvimento de trabalhos futuros envolvendo a aplicação de motores flex como: sistemas de propulsão híbridos, motores com taxa de compressão variável, motores com injeção direta de combustível e motores turbos alimentados.

\section{REFERÊNCIAS}

[1] M F DEMIRBAS and M BALAT, "Recent advances on the production and utilization trends of bio-fuels: A global perspective," ENERGY CONVERSION AND MANAGEMENT, vol. 47, pp. 2371-2381, Setembro 2006.

[2] Avinash Kumar AGARWAL, "Biofuels (alcohols and biodiesel) applications as fuels for internal," PROGRESS IN ENERGY AND COMBUSTION SCIENCE, vol. 33, pp. 233271, Junho 2007.

[3] S. Mani SARATHY, Patrick OSSWALD, Nils HANSEN, and Katharina KOHSEHOEINGHAUS, "Alcohol combustion chemistry," PROGRESS IN ENERGY AND COMBUSTION SCIENCE, vol. 44, pp. 40-102, Outubro 2014.

[4] ANP, "Anuário estatístico brasileiro do petróleo, gás natural e biocombustíveis," Agência Nacional do Petróleo, Gás Natural e Biocombustíveis, 2017.

[5] M GAUTAM and DW MARTIN, "Combustion characteristics of higher-alcohol/gasoline blends," PROCEEDINGS OF THE INSTITUTION OF MECHANICAL ENGINEERS PART A-JOURNAL OF POWER AND ENERGY, vol. 214, 2000.

[6] WD HSIEH, RH CHEN, TL WU, and TH LIN, "Engine performance and pollutant 
emission of an SI engine using ethanol-gasoline blended fuels," ATMOSPHERIC ENVIRONMENT, vol. 36, pp. 403-410, Janeiro 2002.

[7] G NAJAFI et al., "Performance and exhaust emissions of a gasoline engine with ethanol blended gasoline fuels using artificial neural network," APPLIED ENERGY, vol. 86, pp. 630-639, Maio 2009.

[8] PAU BARES, DONALD SELMANAJ, C GUARDIOLA, and C ONDER, "A new knock event definition for knock detection and control optimization," Applied Thermal Engineering, pp. 80-88, Fevereiro 2018.

[9] UNICA, Produção e uso do Etanol combustível no Brasil. São Paulo, 2007.

[10] Brasil. (1931, Fevereiro) Estabelece a aquisição obrigatória de álcool, na proporção de $5 \%$ da gasolina importada, e dá outras providências. [Online]. http://www2.camara.leg.br/legin/fed/decret/1930-1939/decreto-19717-20-fevereiro1931-518991-publicacaooriginal-1-pe.html

[11] Rogério Alessandre de Oliveira Castro, "Nova regulação do mercado de etanol e da indústria de biocombustíveis," in Universitas e Direito, Paraná, 2012, pp. 525-545.

[12] Brasil. (1933, Junho) Crea o Instituto do Assucar e do Alcool e dá outras providências. [Online]. http://www2.camara.leg.br/legin/fed/decret/1930-1939/decreto-22789-1-junho1933-503228-publicacaooriginal-1-pe.html

[13] Brasil. (1938) Torna obrigatória a adição de alcool anidro à gasolina produzida no país, qualquer que seja o método ou processo de sua fabricação, e dá outras providências. [Online]. http://www2.camara.leg.br/legin/fed/declei/1930-1939/decreto-lei-737-23setembro-1938-350748-publicacaooriginal-1-pe.html

[14] Rogério Cerqueira Leite and Luís Augusto Barbosa Cortez, "O etanol combustível no Brasil," Revista Biocombustiveis no Brasil: Realidades e Perspectivas, 2008.

[15] Roberto Grassi Neto, "Contratos Agroindustriais e a Regulamentação Legal da Produção de Biocombustíveis.," in Ensaios sobre os biocombustiveisContratos Agroindustriais e a Regulamentação Legal da Produção de Biocombustíveis.: Annablume, 2010, vol. 2, p. 85.

[16] Brasil. (1975) Institui o Programa Nacional do Álcool e dá outras Providências. [Online]. http://www2.camara.leg.br/legin/fed/decret/1970-1979/decreto-76593-14-novembro1975-425253-publicacaooriginal-1-pe.html

[17] Brasil. (1993) Dispõe sobre a redução de emissão de poluentes por veículos automotores e dá outras providências. [Online]. http://www2.camara.leg.br/legin/fed/lei/1993/lei8723-28-outubro-1993-363267-normaatualizada-pl.html

[18] XD ZHEN et al., "The engine knock analysis - An overview," APPLIED ENERGY, vol. 92, pp. 628-636, Abril 2012.

[19] Uwe KIENCKE and Lars NIELSEN, Automotive Control Systems. Berlin: SpringerVerlag, July 2000.

[20] CORTI ENRICO et al., "Transient spark advance calibration approach," Energy Procedia, vol. 45, pp. 967-976, 2014.

[21] T SARDARMEHNI, J KEIGHOBADI, M B MENHAJ, and H RAHMANI, "Robust predictive control of lambda in internal combustion engines using neural networks," ARCHIVES OF CIVIL AND MECHANICAL ENGINEERING, vol. 13, pp. 432-443, 2013.

[22] S A AL-SAMARRAIE and Y K ABBAS, "Design of electronic throttle valve position control system using nonlinear PID controller," nternational Journal of Computer 
Applications, vol. 4, pp. 27-34, 2012.

[23] YILDIRAY YILDIZ, ANURADHA M ANNASWAMY, DIANA YANAKIEV, and ILYA KOLMANOVSKY, "Spark ignition engine fuel-to-air ratio control: An adaptive control approach," CONTROL ENGINEERING PRACTICE, vol. 18, pp. 1369-1378, 2010 .

[24] JIANGYAN ZHANG, TIELONG SHEN, and RICCARDO MARINO, "Model-based cold-start speed control scheme for spark ignition engines," CONTROL ENGINEERING PRACTICE, vol. 18, pp. 1285-1294, 2010.

[25] J YANKUN and B LIU, "A study on ignition advanced angle control strategy of EFI gasoline engine," SAE technical paper. No. 2010-01-0244, 2010.

[26] CZARNIGOWSKI JACEK, "A neural network model-based observer for idle speed control of ignition in SI engine," Engineering Applications of Artificial Intelligence, vol. 23, pp. 1-7, Fevereiro 2010.

[27] X YUAN, Y WANG, and L WU, "SVM-based approximate model control for electronic throttle valve," IEEE Transactions on Vehicular Technology, pp. 2747-2756, 2008.

[28] E M FRANCESCHI, K R MUSKE, J C PEYTON JONES, and I MAKKI, "An adaptive delay-compensated PID air fuel ratio controller," SAE technical paper. No: 2007-011342, 2007.

[29] I RADUCANU, D AROTARITEI, and L DIMITRIU, "Adaptive control of the fuel injected per cycle and of the ignition advance for the spark ignition engine using fuzzy inferential systems," SAE technical paper. No. 2001-01-3384, 2001.

[30] E LARS and L NIELSEN, "Non-linear model-based throttle control," SAE technical paper, No. 2000-01-0261, 2000. 